\title{
HOMOSSEXUALIDADE MASCULINA NOS PRONTUÁRIOS DO SANATORIO PINEL 1920-1940: um estudo de compreensão dos dispositivos de controle social
}

\author{
MALE HOMOSEXUALITY IN THE PRONOUNS OF THE SANATORIO PINEL \\ 1920-1940: study of understanding the devices of social control
}

\author{
Francisco Arrais Nascimento \\ Larissa de Mello Lima² \\ Daniel Martínez-Ávila ${ }^{3}$
}

\begin{abstract}
RESUMO
Objetivou-se compreender como a partir do desemaranhar das linhas componentes do dispositivo de controle social, sob 0 viés da patologização, componente da tríade pecado-crime-doença foi constituído o universo discursivo acerca das homossexualidades, tomando por alicerce as representações das homossexualidades masculinas a partir dos relatos (prontuários) produzidos por profissionais da saúde vinculados ao sanatório Pinel no período compreendido entre os anos de 1920-1940. Ressalta-se que o comportamento e as percepções do corpo de tais pacientes foram identificados e classificados com o intuito de controlar e justificar a retirada de tais sujeitos do convívio social, sob uma égide discursivamente patologizante. Metodologicamente propôs-se a construção de uma cartografia de documentos com o intuito de identificar segundo Rolnik (1989) paisagens psicossociais, políticas e afetivas. Diante disso, propôs-se adentrar a esfera das discussões de gênero, situando-se teórico-metodologicamente em perspectiva discursivo-desconstrucionista, recorrendo aos estudos pós-estruturalistas de base foucaultiana e também à análise do discurso de orientação Francesa além da relação com as teorizações queer. Logo, se pode compreender que o dispositivo que se transforma e ressignifica de maneira a sobreviver e melhor servir aos desejos dos grupos hegemônicos, se alastrando de forma a tornar impossível que o ser não seja tido como sujeito em sua natureza, criando um sistema excludente e coercitivo que ainda vigora onde os discursos das instituições (Igreja, Estado, entre outras) ecoam e certificam a atuação e manutenção dos dispositivos históricos de controle social, fazendo com que os mesmos sejam introjetados pela sociedade gerando assim sujeitos dóceis e produtivos.
\end{abstract}

Palavras-chave: Dispositivos de Controle Social. Representação. Homossexualidade Masculina. Prontuário do Paciente. Sanatório Pinel.

\begin{abstract}
The objective of this study was to understand how the discursive universe about homosexuality was constituted through the unraveling of the components of the social control device, under the bias of the pathologization, as a component of the triad sin-crime-disease. (records) produced by health professionals related to Pinel sanatorium in the period between 1920-1940. It is emphasized that the behavior and perceptions of the body of such patients were identified and classified with the purpose of controlling and justifying the withdrawal of such subjects from social life, under a discursively pathological aegis. Methodologically it was proposed the construction of a cartography of documents in order to identify according to Rolnik (1989) psychosocial, political and affective landscapes. In view of this, it was proposed to enter the sphere of the gender discussions, situating itself theoretically-methodologically in a discursive-deconstructionist perspective, resorting to Foucaultian-based post-structuralist studies and also to the analysis of the French orientation discourse, as well as the relation with the theorizations queer Therefore, it can be understood that the device that transforms and resigns in a way to survive and better serve the desires of the hegemonic groups, spreading in such a way as to make it impossible for the being not to be considered as subject in its nature, creating a system excluding and (Church, State, among others) echo and certify the performance and maintenance of the historical devices of social control, causing them to be introjected by society, thus generating docile and productive subjects.
\end{abstract}

Keywords: Devices of Social Control. Representation. Male Homosexuality. Patient Record. Sanitorium Pinel.

Artigo submetido em 26/03/2019 e aceito para publicação em 13/03/2020

1 Doutorando em Ciência da Informação pela Universidade. Estadual Paulista “Júlio de Mesquita Filho”, Brasil. ORCID https://orcid. org/0000-0003-4424-8844. E-mail: francisco.arrais.nascimento@gmail.com

2 Doutoranda em Ciência da Informação pela Universidade. Estadual Paulista “Júlio de Mesquita Filho", Brasil. ORCID https://orcid. org/0000-0002-5377-9535. E-mail: larissalima.unesp@gmail.com

3 Professor Assistente Doutor na Universidade. Estadual Paulista "Júlio de Mesquita Filho", Brasil. ORCID https://orcid.org/00000003-2236-553X. E-mail: martinez.avila@unesp.br 


\section{INTRODUÇÃO}

Ao vislumbrar as homossexualidades enquanto pratica, para além do desejo homoerótico, tomando por centro a norma vigente, atribuída a heterossexualidade enquanto "ordem compulsória" (RICH, 1993), adentrando-se assim ao universo dos ditos desvios sexuais, se pode observar que tal pratica têm sido, nos últimos quatro mil anos, nas diferentes civilizações que serviram de matriz à cultura ocidental, rotulada por diversos termos atrozes que refletem o alto grau de reprovação associado a performance erótico-afetiva desviante da norma eleita, a saber: abominação; crime contra a natureza; "crimes contra a moral sexual"; sodomia, "pecado nefando" (Indigno de se nomear; abominável, execrável, execrando, nefário, sodomia, pecado contra a natureza, cópula anal, homossexualidade); vício dos bugres; abominável pecado de sodomia; velhacaria; "descaração"; desvio; (MOTT, 2010), entre outros como: doença, viadagem, frescura, "subversivos morais" (GREEN; QUINALHA, 2014). Tais aspectos vão se ilustrando por meio de ações como as do Papa Inocêncio VIII (1484-1495) que promulgou a bula, Summis desiderantes affectibus, especificamente para justificar e encorajar a caça às "feiticeiras". A bula alegava que os demônios, chamados íncubos (masculinos) e súcubos (femininos), adotavam formas humanas para manter relações sexuais violentas com pessoas desprevenidas, assim causando natimortos, impotência e esterilidade. Qualquer ser humano podia ser um demônio, sobretudo o que fosse atraente e sedutor e que tentasse o outro para a união sexual. [...] mais tarde, acreditou-se que os homossexuais condenados pela inquisição podiam ser filhos de tais uniões (SPENCER, 1999, p.124).

Diante disso, se pode perceber que os discursos que permeiam a construção histórica das homossexualidades não foram consolidados apenas por meio de sermões, leis e edificações. No entanto a tríade pecado-crime-doença aufere largo espeço sobretudo o que fora construído acerca das homossexualidades. Ressalta-se ainda que a norma social eleita outorgou não apenas discursos, mas práticas e punições severas aos praticantes de modalidades alternativas de sexualidade, onde destaca-se neste estudo a homossexualidade como principal forma. Aqui, há um formato de pensar a homossexualidade de forma múltipla, dada a usa multifacetada atuação no âmbito social sob ópticas distintas, acrescentando-se assim o "s", assumindo uma posição que pactua com a compreensão da diversidade, inclusive dentro da própria diferença.

Denizart $(1997$, p. 9) afirma que “[...] a sexualidade é 'uma fantasia passageira', a ser usufruída como bem a entendemos", assim, alicerçando-se sobre discurso pós-estruturalista sob viés foucaultiano 
se pode observar o emergir de identidades de gênero tais como Crossdressers (CD), drag queens, drag kings, orientações sexuais como a dos homens que fazem sexo com homens (HsH), goys, highsexuais e definições de gêneros não binários (masculino e feminino), como os identificados por Nascimento; Leite Junior e Pinho (2016), a saber: agender, aliagender, ambigender, androgine, bigender (female-male), butch non-binary, cristaline, demigender, denboy, demigirl, efêmere, femme non-binary, genderfluid (female-male), genderflux, genderfuck, genderpivot, genderqueer non-binary, graygender, male nonbinary, intergender ou intersex, female non-binary, nanogender, nanoboy, nanogirl, nano-menine, negative, neutrois, pangender, poligender, positive, third gender, transfemale ou Male to Female (MTF), transmale ou Female to Male (FTM) , transvestite non-binary e trigênero, que figuram em um domínio complexo, multifacetado e que ampliam as fronteiras do mesmo lançando luz sobre as zonas de sombra da sociedade, fazendo-se perceber todo um aparato sociocultural de onde emergem atores que podem modificar a forma de como as relações estabelecidas socialmente são representadas, visualizadas e compreendidas, para além da narrativa histórica eleita que apresenta preconceitos e antipatias, sendo norteada por proselitismos sociais e com isso certificando estereótipos. Albuquerque Jr (2009, p.30) ao discorrer acerca do "discurso da estereotipia", é enfático quando afirma que tal discurso,

[...] é um discurso assertivo, repetitivo, é uma fala arrogante, uma linguagem que leva à estabilidade acrítica, é fruto de uma voz segura e autossuficiente que se arroga o direito de dizer 0 que é outro em poucas palavras. 0 estereótipo nasce de uma caracterização grosseira e indiscriminada do grupo estranho, em que as multiplicidades e as diferenças individuais são apagadas, em nome de semelhanças superficiais do grupo.

De forma simplificada concebe-se que toda construção, seja de um sujeito ou de uma identidade, envolve certo grau de normatização, cujo efeito é a produção de excluídos. Tais sujeitos que ocupam a zona de exclusão são definidos por Judith Butler (2002) como corpos abjetos, aqueles cujas vidas não são consideradas legítimas e, portanto, quase impossíveis de se materializar, destacando ainda que 0 corpo abjeto "não se restringe de modo algum a sexo e a heteronormatividade. Relaciona-se a todo tipo de corpos cujas vidas não são consideradas, vidas" e "cuja materialidade é entendida como, não importante" (PRINS; MEIJER, 2002, p. 161).

0 tratamento destinado a certas formas de vida dentro de uma relação de disparidade no âmbito social é descrito por Butler (2010, p. 13), como uma relação onde, "[...] certas vidas não se qualificam como vidas, ou, desde o princípio não são concebidas como vida, dentro de certos marcos epistemológicos, então, tais vidas nunca se considerarão vividas ou perdidas no sentido pleno de ambas as palavras". 
Diante disso, a tríade pecado-crime-doença começa a ser compreendida, pois historicamente observa-se que determinadas existências muitas vezes são negadas, e no decorrer da construção histórica tudo o que fora considerado desviante, indesejado ou errante, fora alocado no espaço da doença, na clausura ou passível de punição por meio jurídico, imprimindo nos sujeitos por meio da violência a punição outorgada pelas instituições sociais. Com isso, as implicações da sociedade disciplinar vastamente trabalhada na obra de Foucault vigoraram tão fortemente no final do século XIX e XX e foram revestidos de novas articulações para sua sobrevivência em uma sociedade pósmoderna, onde se pode observar em suma, o princípio da masmorra é invertido; ou antes, de suas três funções - trancar, privar de luz e esconder - só se conserva a primeira e suprimem-se as outras. Pois ao transformar os dispositivos de controle e punição social a plena luz da sociedade e assegurar o olhar de um vigia (a própria sociedade) que captam melhor que a sombra que protegia, a visibilidade torna-se uma armadilha (FOUCAULT, 2005). Tal afirmação emerge socialmente com a figura do especialista (0 religioso, o médico, o juiz), que tem em si o poder de disciplinar, trancar e punir os sujeitos que não se enquadram na norma vigente, fazendo uso da confissão como ferramenta do dispositivo.

Logo, é impossível chegar em tal nível de compreensão acerca do domínio das sexualidades e não se indagar como a construção histórica privilegiou uma pratica (heterossexualidade) em detrimento das outras (homossexualidades). Sob orientação das linhas foucaultianas, é imprescindível compreender que, aquilo que foi dito (discurso) emite efeito e reverbera como "verdade", uma vez que não existe verdade absoluta, mas sim um consenso acerca de determinado assunto onde um grupo hegemônico compartilha e o tornam verdade, não sendo passível de existência fora da relação de poder estabelecida. Logo, ao suscitar a percepção de que existem discursos hegemônicos que regulam, normatizam, instauram normas e produzem "verdades" e assim prevalecem e são perpetuados. Spitzner (2014) norteado pelas linhas de Pollak (1989) demonstra o efeito da atuação de tal mecanismo sob a construção da "imagem" que a sociedade deseja perpetuar, onde "[...] a fronteira entre 0 dizível e 0 indizível, o confessável e o inconfessável, separa uma memória coletiva subterrânea da sociedade civil dominada ou de grupos específicos, de uma memória coletiva organizada que resume a imagem que uma sociedade majoritária ou o Estado desejam passar e impor".

Scott (1995) traz a premissa de que o discurso é um instrumento de orientação do mundo, mesmo se não é anterior à orientação da diferença sexual, compreendida no contexto desta pesquisa enquanto mecanismo de controle social, apresentando-se como parte do dispositivo histórico, onde se normaliza o corpo social por meio da linguagem. Logo se pode vislumbrar que não há discurso 
isento ou estabelecido fora de qualquer relação de poder. Para isso é preciso compreender o regime de "verdade" da época (tempo) e local (espaço) em que tal relação fora estabelecida e principalmente o lugar que serve de cenário para tal discurso. Nenhuma "verdade" é, portanto, neutra, soberana e imutável (FOUCAULT, 2005).

Dessa forma, o estudo aqui apresentado objetiva compreender como a partir do desemaranhar das linhas componentes do dispositivo de controle social, sob o viés da patologização, componente da tríade pecado-crime-doença foi constituído o universo discursivo acerca das homossexualidades, tomando por alicerce as representações das homossexualidades masculinas a partir dos relatos (prontuários) produzidos por médicos psiquiatras vinculados ao sanatório Pinel no período compreendido entre os anos de 1920-1940. Ressalta-se que o comportamento e as percepções do corpo de tais pacientes foram identificados e classificados com o intuito de controlar e justificar a retirada de tais sujeitos do convívio social, sob uma égide discursivamente patologizante.

\section{METODOLOGIA}

Assim, em função dos objetivos desta pesquisa, a metodologia mais apropriada para ser utilizada é a que propicia uma abordagem discursiva, trazendo contribuições de Albrechetsen e Hjørland (1995, 1997, 1999, 2002), Tennis (2012), Kobashi (1994) e Guimarães (2008) no âmbito da Ciência da Informação. Além das contribuições de Michel Pêchex, e os discursos que entram em jogo na construção dos documentos e discursos existentes, assim como as linhas de Orlandi (1996, 2002, 210) e de Charaudeau (2013), as quais não se preocupam com a quantificação na construção dos dados, pois estes são reunidos em função de sua qualidade, de suas características, exigindo uma tarefa de conceituação. Nesse sentido, a análise do discurso captura, modifica e dissemina acontecimentos, opiniões e ideias do presente, organizando o futuro, autenticando o passado - memória - e realizando uma leitura desses fatos do presente no futuro. Essa metodologia de análise "[...] concebe a linguagem como mediação necessária entre o homem e a realidade natural e social [cujo] discurso torna possível à permanência, a continuidade, o deslocamento e a transformação do homem e da realidade" (ORLANDI, 2002, p. 15).

Logo, em um primeiro momento, propõe-se a construção de uma cartografia de documentos com 0 intuito de identificar segundo Rolnik (1989) paisagens psicossociais, políticas e afetivas. Diante disso, propõe-se adentrar a esfera das discussões de gênero. 0 uso de "gênero" enfatiza todo um 
sistema de relações que pode incluir o sexo, mas não é diretamente determinado pelo sexo, nem determina diretamente a sexualidade. 0 termo Gênero se ajusta à terminologia científica das ciências sociais, dissociando-se assim, da política (supostamente ruidosa) do feminismo (SCOTT, 1995), situando-se teórico-metodologicamente em perspectiva discursivo-desconstrucionista, recorrendo aos estudos pós-estruturalistas de base foucaultiana, além da relação com as teorizações queer.

A cartografia, nesse caso, acompanha e se faz ao mesmo tempo que o elemento desconstrutor de certas realidades onde ocorre uma realocação e ressignificação dos sentidos e a formação de outros. Realidades que se desvelam para expressar afetos nos contextos contemporâneos, em relação aos quais os universos vigentes tornaram-se obsoletos. No entanto, fica claro o uso de tal metodologia exploratória como forma de levantamento de fontes e registros que poderão embasar o estudo aqui apresentado pois as memórias e registros das homossexualidades são colocadas a margem ou alocadas como fontes secundárias e sem importância pela norma vigente. Assim, ao eleger tais registros como prioritários e de suma importância subverte-se a norma impondo o não esquecimento de tais memórias, fazendo com que todo um construto venha a emergir no contexto social em que está inserido sob uma posição diferenciada e de forma subterrânea.

Com isso, norteado pelas linhas de Deleuze (1990) que reafirma a cartografia como um método para além de seus usos limitados dentro da Geografia, onde o autor aloca a mesma como uma alternativa para "desemaranhar" as linhas que compõe um dispositivo, uma vez que o mesmo é compreendido enquanto uma tessitura complexa e embrincada que fora construído e ressignificado no âmbito social sob camadas de construção histórica, como forma de permanência de forma funcional e subserviente na relação de poder/saber. Ressalta-se que,

[...] o dispositivo, portanto, está sempre inscrito em um jogo de poder, estando sempre, no entanto, ligado a uma ou a configurações de saber que dele nascem, mas que igualmente 0 condicionam. É isto, o dispositivo: estratégias de relações de força sustentando tipos de saber e sendo sustentadas por eles. (FOUCAULT, 2000, p.246).

Logo,

[...] desemaranhar as linhas de um dispositivo é, em cada caso, traçar um mapa, cartografar, percorrer terras desconhecidas, é o que Foucault chama de 'trabalho de terreno'. É preciso instalarmo-nos sobre as próprias linhas, que não se contentam apenas em compor um dispositivo, mas atravessam-no, arrastam-no, de norte a sul, de leste a oeste ou em diagonal. (DELEUZE, 1990 p.1)

Assim, a cartografia documental foi capaz de identificar 11 (onze) casos, que constituíram a amostra do estudo, ver Quadro 2. 0 primeiro passo após a cartografia de documentos, consistiu na 
leitura cuidadosa e (re)leitura da materialidade empírica a fim de tentar captar os significados que não tenham sido percebidos ou não ditos. Esta fase de leituras contínuas permitiu-se ao analista encontrar palavras repetitivas, expressões e frases que possam representar situações de forma mais ou menos coerente e de significado similar, metáforas que possam implicar imagens específicas ou mesmo palavras com significados particulares. Também traz à tona semelhanças e diferenças, apontando quais os efeitos discursivos podem estar implicados no discurso documental em questão.

Para falar-se de efeitos discursivos antes realiza-se uma breve contextualização histórica e conceitual da área. Uma vez que o título Análise do Discurso está comumente associado a um conjunto de técnicas de pesquisa que normalmente admitem algum tipo de influência ou inspiração das obras de Foucault. Neste sentido, deve-se deixar bem claro desde o princípio que Foucault nunca estabeleceu um conjunto de pautas sistemáticas ou instruções de como realizar sua análise do discurso, aspecto que entra em consonância com a própria atuação e coerência intelectual do autor: "Eu tomo cuidado de não ditar como as coisas deveriam ser" (FOUCAULT, 1994, p. 288).

Apesar deste alerta, isto não impediu que numerosos estudiosos e leitores de Foucault tenham identificado os passos metodológicos que ele utilizou em seus diferentes estudos, para extraí-los e distingui-los de outros métodos. Foucault sempre foi explícito e detalhado - pode-se até dizer metódico - com respeito a suas próprias obras, e isto permitiu criar uma escola de estudiosos. Como Niels Åkerstrøm Andersen (2003, p. 1) afirma: "Foucault falhou fundamentalmente em um aspecto. Ele fundou uma escola de pensamento, embora a sua ambição explícita fosse a de não fazer isso".

Mutável e fluido como as categorias estudadas por Foucault, o método por ele utilizado que será denominado por conveniência de análise do discurso - também variou em seus diferentes trabalhos. Assim, podem-se identificar, no mínimo, as variantes de análise arqueológica, análise genealógica, tecnologia de autoanálise (self-technologyanalysis), e análise dispositiva (também propondo, dentre outras possíveis estratégias, a análise estética, (ANDERSEN, 2003, p. 8). Cada estratégia nos trabalhos de Foucault, afirma Andersen, progressivamente substitui a anterior embora Andersen ainda afirme que não apenas estas e outras estratégias podem ser combinadas, mas também que "[...] a análise genealógica não pode ser separada da análise arqueológica”, sendo assim impossível "[...] conduzir uma análise arqueológica do saber sem combiná-la com uma análise genealógica" (ANDERSEN, 2003, p. 17). Nos textos de Foucault, a análise arqueológica e a genealógica usualmente são separadas em dois estudos diferentes, o primeiro tomando a forma 
de um compêndio em "Arqueologia do saber" (1969), e o segundo, uma subsequente modificação deste compêndio em "Nietzsche, la généalogie, l'histoire" de 1971 ("Nietzsche, Genealogy, History" em inglês, FOUCAULT, 1984). Em uma interpretação possível, a análise genealógica pode ser considerada como uma dimensão histórica da arqueologia do saber. Entretanto, Foucault já havia introduzido alguns dos conceitos chave da análise genealógica antes da publicação de "Nietzsche, Genealogy, History."

Embora a análise do discurso de Foucault seja separada de maneira frequente em arqueológica e genealógica, na prática não é possível separar-se claramente estes dois estágios (nem mesmo quando identificadas como duas estratégias de análise discursiva (ANDERSEN, 2003, p. 17). Entretanto, alguns autores, como John Budd, apontam algumas diferenças entre as duas abordagens: "Arqueologia e genealogia não são certamente mutuamente excludentes; elas exibem, contudo, alguns aspetos focais diferentes" (BUDD, 2006, p. 74). Mais especificamente, e de acordo com Budd, "a abordagem genealógica examina de maneira mais explícita os caminhos que o discurso trilha não tendo em vista meramente 0 que 0 conhecimento reivindica, mas as relações baseadas no poder que definem ‘objetividade' e que tentam legitimar as reivindicações do conhecimento”. Para Jack Andersen e Laura Skouvig, que também combinaram arqueologia e genealogia em suas pesquisas, a diferença entre ambas as abordagens poderia ser que "[...] a abordagem arqueológica de Foucault trabalha com a construção de discurso, e a abordagem genealógica foca na questão do poder" (ANDERSEN; SKOUVIG, 2006, p. 306).

Com relação a "Nietzsche, Genealogy, History”, Foucault aceita a crítica da história que Nietzsche fez através de todas as reflexões sobre a natureza do bem, do mal e da moralidade. Foucault (1984), assim, apresenta a genealogia como

[...] o registro de eventos fora de qualquer finalidade monótona; ela deve procurar, então, nos lugares menos promissores, nos quais tende-se a sentir sem sentimentos históricos, amor, consciência, instintos; deve ser sensitiva a ocorrência deles, não de forma a traçar a curva gradual de sua evolução, mas para isolar as diferentes cenas nas quais eles se engajam em diferentes papeis. Finalmente, a genealogia deve definir mesmo aquelas instâncias nas quais estes estão ausentes, o momento no qual eles permanecem irrealizados (Platão, em Siracusa, não se tornou Mohamed). (FOUCAULT 1984, p.76).

A AD defende que uma mesma palavra ou frase pode implicar um significado distinto dependendo da forma como se insere na frase ou na continuação ou antecedência de outra. Segundo Orlandi (2010, p. 26), "[...] a análise do discurso visa à compreensão de como um objeto simbólico produz sentidos, como ele está investido de significância para e por sujeitos". 
Com isso, após a identificação dos discursos, que passaram pelas ações discursivas emitidas, o passo seguinte da análise, considerado um dos mais importantes, consistiu no estudo de suas implicações, isto é, de seus efeitos discursivos. Essa perspectiva analítica visa “[...] fazer compreender como os objetos simbólicos produzem sentidos, analisando assim os próprios gestos de interpretação que ela considera como atos no domínio simbólico, pois eles intervêm no real do sentido" (Orlandi, 2010 p. 26), não permanecendo na interpretação, mas trabalhando seus limites e mecanismos como parte dos processos de significação.

\section{RESULTADOS E DISCUSSÕES}

No processo de "desemaranhar" o dispositivo histórico de coerção social, o qual fora utilizado em larga escala pelo sistema manicomial brasileiro no século XX, esboçando um cenário complexo que se instaurou no Brasil, no final do século XIX e início do século XX, sendo perpetuado por meio de ecos discursivos na área médica, se faz necessário identificar como tal mecanismo funcionava e que instituições adotaram as práticas de tratamento das homossexualidades entre outros comportamentos que estavam inscritos no hall de práticas passiveis de tratamento por estas instituições.

Reverter as engrenagens do tempo de forma a retornar ao período desejado, não é uma possibilidade. No entanto ao se partir de tempos hodiernos em direção ao passado de forma a capturar os ecos discursivos, identificar as práticas e compreender como todo o mecanismo do dispositivo atuou até a segunda metade do século XX, torna-se uma alternativa de reconstrução do discurso da patologização em torno das homossexualidades em uma tentativa de compreender a tessitura construída no decorrer da história.

Logo, ao se discorrer acerca das patologias e disfunções de natureza mental como forma enquadradas as homossexualidades, o Manual Diagnóstico e Estatístico de Transtornos Mentais (DSM) torna-se ferramenta fundamental, uma vez que o mesmo data do início da segunda metade do século $X X$, período esse, próximo do recorte cronológico e onde ainda se pode encontrar um forte movimento manicomial no Brasil e evidencias de que o discursos patologizante acerca das homossexualidades era vigente e alicerçava praticas medico cientificas.

Com isso, o quadro 1 elaborado por Nascimento, Leite Junior e Pinho (2015), registra a evolução da tipificação e classificação das temáticas de Gênero e Sexualidade no Manual Diagnóstico e Estatístico de Transtornos Mentais (DSM). 
Quadro 1: Evolução da tipificação e classificação das temáticas de gênero e sexualidade no Manual Diagnóstico e Estatístico de Transtornos Mentais (DSM)

\begin{tabular}{|c|c|c|c|c|}
\hline Versão & Ano & $\begin{array}{l}\mathrm{N}^{0} \text { categorias } \\
\text { diagnósticas }\end{array}$ & $\begin{array}{l}\mathrm{N}^{0} \text { de } \\
\text { paginas }\end{array}$ & Tipologias e Classificações \\
\hline DSM - I & 1952 & 106 & 130 & $\begin{array}{l}\text { Homossexualismo, o travestismo, } \\
\text { pedofilia, fetichismo e sadismo sexual } \\
\text { (incluindo estupro, agressão sexual, } \\
\text { mutilação) }\end{array}$ \\
\hline DSM - II & 1968 & 182 & 134 & $\begin{array}{l}\text { Perturbação da orientação sexual. Desvio } \\
\text { sexual }\end{array}$ \\
\hline DSM - III & 1980 & 265 & 494 & $\begin{array}{l}\text { Transtornos psicossexuais, subdivididos em } \\
\text { quatro categorias: Gender Identity Disorders, } \\
\text { Paraphilias, Psychosexual Dysfunctions e } \\
\text { Other Psychosexual Disorders. }\end{array}$ \\
\hline DSM-III-R & 1987 & 292 & 567 & $\begin{array}{l}\text { "Transtornos de identidade de gênero" } \\
\text { com as especificações: "em crianças" e } \\
\text { "em adolescentes ou adultos" ao invés de } \\
\text { travestismo. }\end{array}$ \\
\hline DSM - IV & 1994 & 297 & 886 & $\begin{array}{l}\text { "Sexual and Gender Identity Disorders", } \\
\text { sendo composto por } 27 \text { transtornos, alguns } \\
\text { apresentando mais de uma subdivisão, } \\
\text { agrupados em Sexual Dysfunctions, } \\
\text { Paraphilias e Gender Identity Disorders }\end{array}$ \\
\hline DSM - 5 & 2013 & 303 & 970 & $\begin{array}{l}\text { Disfunções Sexuais, Disforia de Gênero e } \\
\text { Transtornos Parafílicos }\end{array}$ \\
\hline
\end{tabular}

Fonte: Elaborado por Nascimento, Leite Junior e Pinho, 2015.

No tocante a esta publicação que norteia os diagnósticos na área psiquiátrica, sendo amplamente utilizado, a evolução da tipificação e classificação das temáticas de gênero e sexualidade servem com subsidio para a compreensão do que está sendo trabalhado, com isso ao analisar cronologicamente os DSM's publicados tem-se as seguintes recomendações, DSM - I encontra-se a seguinte especificação: "O diagnóstico vai especificar os tipos de comportamentos patológicos, como o homossexualismo, o travestismo, a pedofilia, o fetichismo e o sadismo sexual (incluindo estupro, agressão sexual, mutilação)" (APA, 1952, p. 39).

Em 1968 publicou-se o DSM - II, no entanto o DSM - II é muito próximo ao DSM - I, ambos apresentando uma forte influência da psiquiatria psicodinâmica que era predominante na época, embora já se possa perceber perspectivas biológicas e conceitos dos sistemas de classificação.

0 DSM - II é revisto em 1974, impulsionado por ações desenvolvidas pelos ativistas dos direitos dos homossexuais contra a Associação Americana de Psiquiatria - APA, que dá início a revisão 
no ano de 1970. Apresentado com dados de pesquisadores como Alfred Kinsey e Evelyn Hooker, a sétima impressão do DSM - II, em 1974, já não tinha listado em suas páginas a homossexualidade como uma categoria de desordem. 0 diagnóstico foi substituído com a categoria de "perturbação da orientação sexual" sendo listados os seguintes desvios: "homossexualidade", "fetichismo", "pedofilia", "travestismo", "exibicionismo", "voyeurismo", "sadismo", "masoquismo", "outros desvios sexuais".

No DSM - II, a definição se transforma, sendo utilizada esta categoria para os indivíduos que possuem interesses dirigidos sexualmente para algo/alguém que não sejam pessoas do sexo oposto e em suas relações sexuais não agem associados diretamente ao coito, mas são realizados em circunstâncias como necrofilia, pedofilia, sadismo sexual e fetichismo (APA, 1968, p. 44).

ODSM - III publicado em 1980 (APA, 1980), logo passou a ser utilizado internacionalmente, sendo chamado de revolução ou transformação em psiquiatria. Ainda sobre o DSM - III o grupo "parafilias" praticamente repetia a lista publicada no DSM - II, que por sua vez nada mais fazia do que listar as antigas "perversões" delineados no final do século XIX. A novidade está no fato da "Homossexualidade" deixar a rubrica "parafilia", transformando-se em "Homossexualidade ego-distônica" alocado em "Outros transtornos psicossexuais". Os dois movimentos, de permanência e transformação, apontam para uma questão de suma relevância na história das classificações psiquiátricas.

Em 1987, o DSM-III-R foi publicado como uma revisão do DSM - III (APA, 1987), as categorias foram renomeadas e reorganizadas, e mudanças significativas nos critérios foram feitas, como é o caso da "Perturbação da Orientação sexual" removida e substituída por "desordem sexual não especificada de outra forma", que pode incluir "sofrimento persistente e marcado sobre sua orientação sexual". Observa-se que o número de transtornos cresceu, ao invés de nove transtornos do DSM - III encontram-se 22 "Transtornos psicossexuais", subdivididos em quatro categorias (Gender Identity Disorders, Paraphilias, Psychosexual, Dysfunctions e Other Psychosexual Disorders).

Em 1994, o DSM - IV foi publicado (APA, 1994), onde se pode observar a inclusão de um critério de significância clínica para quase metade das categorias, o que exigiu que os sintomas causavam "sofrimento clinicamente significativo ou deficiência nas áreas social, ocupacional ou outras áreas importantes de funcionamento “. Alguns diagnósticos de transtorno de personalidade foram apagados ou movidos para o apêndice. A "revisão de texto" do DSM - IV, conhecido como o DSM-IVTR, foi publicado em 2000 (APA, 2000). Nesta última versão o tipo de transtorno passou a se intitular "Sexual and Gender Identity Disorders", dele fazendo parte 27 transtornos (vários com mais de uma subdivisão), agrupados em Sexual Dysfunctions, Paraphilias e Gender Identity Disorders. 
A quinta edição do DSM foi publicada em 2013 (APA, 2013) e no que se refere aos temas específicos (Gênero e sexualidade) o DSM - 5 fragmentou o capítulo Transtornos Sexuais e da Identidade de Gênero dando origem a três novos capítulos: Disfunções Sexuais, Disforia de Gênero e Transtornos Parafílicos. No atual manual as Disfunções Sexuais são um grupo de transtornos heterogêneos tipicamente caracterizados por uma perturbação clinicamente significativa na capacidade de uma pessoa para responder sexualmente ou de sentir prazer sexual. É possível que um indivíduo apresente mais de uma disfunção sexual ao mesmo tempo, havendo ainda disfunções específicas de cada gênero. Para evitar o risco de superestimar as incidências dessas disfunções, a atual versão do manual requer uma duração mínima de seis meses, além de incluir critérios mais precisos para avaliar a severidades dos sintomas.

A Disforia de Gênero aparece no manual como um diagnóstico que descreve os indivíduos que apresentam uma diferença marcante entre o gênero experimentado/expresso e o gênero atribuído. A mudança na nomenclatura do DSM - 5 enfatiza o conceito de incongruência de gênero como algo a mais do que a simples identificação com o gênero oposto apresentada no DSM-IV-TR como Transtorno da Identidade de Gênero. 0 DSM - 5 trouxe maior detalhamento aos critérios diagnósticos, além de utilizar critérios específicos para identificar a Disforia de Gênero na Infância.

No que diz respeito aos subtipos, o manual aboliu uso dos especificadores que descreviam a orientação sexual destes indivíduos, especialmente porque a diferenciação não se mostrou clinicamente útil. Novos especificadores foram introduzidos ao diagnóstico: a presença de condições médicas que interferem no desenvolvimento de caracteres sexuais (ex.: síndrome de insensibilidade a andrógenos, hiperplasia adrenal) deve ser descrita como "com um Transtorno do Desenvolvimento Sexual”; a condição de indivíduos que realizaram a transição para o gênero desejado passou a ser listada como "Pós-Transição".

0 DSM - 5 (APA 2013) incluiu um capítulo para tratar especificamente dos Transtornos Parafílicos, distinguindo-os conceitualmente das Parafilias que eram apresentadas entre os Transtornos Sexuais e da Identidade de Gênero no DSM-IV-TR. A atual versão do manual reconhece as Parafilias como interesses eróticos atípicos, mas evita rotular os comportamentos sexuais não-normativos como necessariamente patológicos.

Com isso, após a leitura dos documentos que podem assegurar ou mesmo nortear um diagnóstico e uma possível intervenção medica, não se encontrou indicações para tanto. Logo, se no âmbito legal não havia lastro para arraigar o argumento que assegurasse uma intervenção clinica por meio do cerceamento de liberdade e/ou recolhimento a uma instituição de tratamento psiquiátrico como 
Arbex (2013) ao investigar o Hospital Colônia de Barbacena, tido como o maior hospital psiquiátrico do Brasil no período, que fora fundado em 1903 na cidade de Barbacena - MG, pode encontrar denúncias, como as reportagens "A sucursal do inferno" (revista 0 Cruzeiro, 1961) do repórter José Franco, com imagens do fotógrafo Luiz Alfredo e "Os porões da loucura" (jornal Estado de Minas Gerais, 1979) do Hiram Firmino, além do documentário "Em Nome da Razão", de Helvécio Ratton, filmado em 1979 que buscavam uma solução para tratamento destinado aos internos daquela instituição? (ARBEX, 2013).

0 alarde de tais documentos não se ancora apenas na data em que foram publicados, mas na forma persistente e na duração de tal tratamento destinado aos ditos "loucos" e quem eram esses ditos "loucos". Segundo Arbex (2013, p. 23),

[...] cerca de $70 \%$ não tinham diagnóstico de doença mental. Eram epiléticos, alcoolistas, homossexuais, prostitutas, gente que se rebelava, gente que se tornara incômoda para alguém com mais poder. Eram meninas grávidas, violentadas por seus patrões, eram esposas confinadas para que o marido pudesse morar com a amante, eram filhas de fazendeiros as quais perderam a virgindade antes do casamento. Eram homens e mulheres que haviam extraviado seus documentos. Alguns eram apenas tímidos. Pelo menos trinta e três eram crianças.

A partir de tais linhas e documentos se pode vislumbrar uma segunda força atuando em prol do bom desempenho do dispositivo de controle, uma vez que não se pode por meio legal (instituições jurídicas) remover aqueles que se tornam incômodos, criam-se meios amparados em mecanismos (médico e religioso) que compõe o dispositivo para que se torne legal e o objetivo da "higienização" seja alcançado, ao bel prazer daqueles que detém o poder.

Foucault (1988) em sua analogia acerca da nau dos loucos que nunca aportará, já aponta um possível caminho do tratamento social acerca da patologização. Se antes a lepra (Hanseníase) era tratada por meio de ilhas e colônias de isolamento onde os sujeitos acometidos ou que simplesmente apresentassem sintomas característicos de tal patologia eram cerrados e cerceados do convívio social em prol da manutenção da "saúde" dos ditos sãos. No caso dos loucos não fora diferente, apenas se ressignificou e institucionalizou por meio do discurso medico cientifico da época. No entanto isso não emancipa tais ações de sua carga perversa, ideológica e política, uma vez que o que se busca não é apenas a "higienização", mas o condicionamento da vida do outro sob a égide do grupo dominante.

\section{SANATÓRIO PINEL}

Não obstante do que fora identificado até o dado momento, o Sanatório Pinel de Pirituba - SP, foi inaugurado em 1929, pela família de Antonio Carlos Pacheco e Silva, era uma instituição privada e 
voltada para classes mais abastardas da sociedade contribuindo de forma decisiva para os discursos de patologização em torno das homossexualidades, no Brasil e seu arquivo traz vasta comprovação das práticas e registros das mesmas.

Ao ser internado na instituição, a família ou pessoa responsável pelo paciente respondia ao questionário que dava aos especialistas condições de análise dos antecedentes do paciente. No quadro 2, se pode observar a lista de casos analisados, com suas informações básicas.

Quadro 2: Casos que compõe a amostra do estudo

\begin{tabular}{|c|c|l|l|l|}
\hline$N^{0}$ & Caso & \multicolumn{1}{|c|}{ Paciente } & \multicolumn{1}{|c|}{ Entrada } & Ordem \\
1 & 139 & Reverendo Macário & 12 set. 1930 & 09579 \\
2 & 216 & Adalberto de Oliveira & 30 jan. 1931 & 09581 \\
3 & 760 & Sydney da Silva Freire & 1 ago. 1933 & 09595 \\
4 & 1126 & Napoleão Biscaldi & 17 jan. 1935 & 09606 \\
5 & 1812 & Bernardino de Campos Araujo & 10 ago. 1937 & 09625 \\
6 & 1990 & Armando Sales de Oliveira Filho & 24 mar. 1938 & 09630 \\
7 & 2479 & Octávio Barros de Oliveira & 18 nov. 1939 & 09643 \\
8 & 2584 & Mário Barreto Xavier & 11 mar. 1940 & 09646 \\
9 & 3074 & Octávio Batista Silva & 26 jan. 1940 & 09660 \\
10 & 3571 & Renato Esteves de Almeida & Jun. 1943 & 09674 \\
11 & 3781 & João Narciso Gonçalves & 31 jan. 1944 & 09681 \\
\hline
\end{tabular}

Fonte: Elaborado pelos autores, 2018.

Em setembro de 1930 deu entrada no sanatório o Religioso Macário, o mesmo fora descrito como sendo um "individuo de estatura avantajada e de forte compleição esquelética e muscular", de descendência alemã, o reverendo internou-se por própria conta, não sendo levado por nenhum parente ou por força policial, mas sim por outros religiosos, sob alegação de que o mesmo teria "infringido as regras da boa moral, por pensamentos e actos pecaminosos que praticou" (Prontuário de Macário S. (Exame Mental), caso $n^{0}$ 139, ordem C9579. Arquivo do Estado de São Paulo, Fundo Sanatório Pinel). Fez uso por diversas vezes uso da imagem religiosa para que fosse removido do sanatório por ordens superiores do abade de São Bento, apelo não ouvido.

Em seu prontuário o mesmo foi identificado como sendo

[...] padre do mosteiro de São Bento. Veio para o Brasil há muitos anos. Consta que na Alemanha entregava-se a práticas homossexuais. Por esse motivo viu-se cercado de rigorosa vigilância nos primeiros tempos que se sucederam a sua chegada ao Brasil. Aos poucos, porém, foi captando a confiança de seus superiores de modo a gosar, ultimamente, 
de bastante liberdade. Entregava-se com afinco ao mister de ensinar meninos pobres (jornaleiros, aprendizes de marinheiro) e sob esse pretexto tinha ocasião de exercer a perversão sexual que se tronava latente por algum tempo, mas que nunca havia desaparecido. Em cerca ocasião contraiu um cancro luético na região perineal, o que até certo ponto fala a favor de pederastia passiva.

0 interno revelou sua predileção por jovens e crianças (pedofilia), e que poderia ter seus desejos revelados por um jovem, por isso optou pelo internamento. 0 reverendo Macário esteve internado no sanatório Pinel por quatro vezes sendo a última em 31 de maio de 1938, quando descrito como um senhor de idade avançada e pré-senil.

0 caso do Padre Macário traz em si todo um aparato sócio cultural de construtos e instituições que influenciaram não apenas a sua percepção de sua condição, mas a de outros internos sob 0 mesmo estado. Suas práticas eram condenáveis socialmente e não eram aceitas pela instituição religiosa a qual o mesmo fazia parte, colocando o reverendo em uma condição de isolamento social que lhe era desagradável e que o expunha a uma existência condicionada, em que o mesmo poderia retornar a sociedade desde que abrisse mão dos desejos e práticas que mantinha, caso contrário o mesmo permaneceria em claustro, sendo o mesmo retirado da vista da sociedade e de seus superiores, o que era confortável para aqueles que o viam como indesejado ou motivo de vergonha e escarnio social.

Não diferente do reverendo Macário, o paciente Adalberto de Oliveira, descrito como branco, de estatura mediana, com 20 anos de idade no período do internamento, nascido em Uberlândia - MG, teve em seu prontuário registrado todo um histórico e do dito diagnostico do mesmo para além das representações acerca dele, a saber:

Descreve bem a sua vida com uma voz de tonalidade afeminada [...]. Diz que tornou-se pederasta passivo há quatro anos contra sua vontade e por capricho, para desmoralizar 0 pae com o qual não combinava. Procurava sempre, que seus actos de passividade fossem observados pelo pae ou ao menos delles ficasse sciente. Affirma pereptoriamente que não sente prazer e que não é invertido constitucional e assim praticou exclusivamente como vingança de muitos actos do pae que o contrariavam. Foi somente com cinco pessoas que teve relações durante esses quatro anos. Elle mesmo quem os convidava, explicando 0 motivo porque assim procedia. Taes são as informações que presta a seu respeito. A nosso ver procura dissimular a perversão, allegando motivo que julga justo e como único meio de vingança ao pae. É de humor variável, pois a qualquer contrariedade chora e logo depois ri quando o motivo se apresenta. Diz que precisa tratar-se, mas que para isso não havia necessidade de internação, estando revoltado com o pae por querer deixa-lo internado por mais de um mez. Si assim o pae proceder, quando voltar ao lar continuara a praticar o coito anal para desmoralizar a família. Não apresenta perturbações mentaes. Tem se conduzido com relativo comportamento no Sanatório, pois tem liberdade e nunca procurou evadirse. É de carater débil e temperamento irascível, pois as contrariedades são acompanhadas sempre de chôro. Não resta dúvida que se trata de um "invertido sexual", sem distúrbios mentaes, tendo contrahido syphilis por coito anal. 
Diferente do reverendo o paciente Adalberto tinha a pratica homossexual, apesar de não ter a homossexualidade como identidade de gênero, tendo o mesmo sido internado no sanatório pelo próprio pai, com o intuído de esconde-lo da sociedade, fato esse compartilhado entre os prontuários analisados, fato esse embasado pelo texto registrado e que o autor coloca em destaque onde o médico afirma que o paciente não apresenta perturbações mentais, logo o que justificaria seu internamento em uma instituição psiquiátrica ou o cerceamento de sua liberdade? Tal argumento é reforçado pela justificativa apresentada pelo paciente acerca de sua sexualidade, o mesmo afirma que se tornou homossexual passivo por vingança de seu pai, logo o caráter desmoralizante de sua orientação sexual e 0 alto grau de reprovação social, era utilizado como forma de se vingar de seu pai, pai este que 0 internara no sanatório. Com isso perceber-se que o sanatório e seu tratamento da homossexualidade na verdade também obedecia a proselitismos sociais sendo o mesmo uma forma de esconder aquilo que é indesejado.

0 prontuário de Sydney da Silva Freire, caso $n^{0} 760$, de 1 de agosto de 1933, sob o número de ordem 09595, Arquivo do Estado de São Paulo, Fundo Sanatório Pinel, é rico em detalhes e informações acerca de seu histórico médico,

\begin{abstract}
Tem quinze anos apenas e já tantos foram os atos anormais praticados, que a necessidade de internação se impoz de modo categórico. Sempre se revelou pouco propenso ao estudo, nunca tendo se importado com as admoestações dos seus pais e professores. Ultimamente em casa deu para subtrair somas em dinheiro e mesmo objetos de pequeno volume que pudesse vender. Gastava 0 que tinha no bolso, com a maior facilidade e sem noção absolutamente do valor do dinheiro. Repreendido por esses fatos, simulava suicídio, aramando scenas teatraes, principalmente quando estavam só em casa sua mãe e sua irmã. Entrou no Sanatório muito pálido e abatido, asseverando a sua progenitora que ele entrega-se excessivamente a prática do onanismo. Não deu a menor mostra de constrangimento por se ver internado, perguntando logo si havia jogo de ping pong no Sanatório. Ao ter uma resposta afirmativa ficou muito contente asseverando que sentia-se perfeitamente a vontade no novo ambiente em que ia viver. Fez logo camaradagem com os demais pensionistas, mostrando-se até excessivamente expansivo, procurando abraçar efusivamente a estes e aos enfermeiros. Dias depois de internado, procurou submeter-se a um ato de pederastia passiva, só não se consumando 0 fato, pela intervenção oportuna de um empregado da casa. Surpreendido em flagrante, não se mostrou tão acabrunhado, como era de se supor, encarando o incidente com uma certa naturalidade. Mostra-se apreciavelmente orientado, respondendo as perguntas que Ihe são feitas de modo aceitável, embora a idade mental pareça uns três anos menos que a que tem. A afetividade e a iniciativa estão bastante comprometidas, deixando tudo ocorrer a sua revelia. Não parece ser portador de alucinações ou ilusões. Em suma, trata-se de um menino em um estado atípico de degeneração, portador de sinais físicos de lues hereditária.
\end{abstract}

0 caso de Sydney da Silva Freire não se distancia de todos os outros analisados em função das características que o mesmo possui. 0 fato que chama atenção é que o rapaz tem apenas 15 anos de idade e que um dos motivos argumentados por seu pai para seu internamento é que o mesmo pratica masturbação com frequência. Segundo Silva (2016, p. 18) “[...] o destino de Sydney não escapou aos 
interesses da dinâmica social de sua época: o controle das doenças, do corpo, dos comportamentos e da sexualidade era ordem do dia".

\section{CONSIDERAÇÕES FINAIS}

A pós o termino das analises, compreende-se que o que Foucault apontou como um biopoder emerge socialmente no período analisado e ainda ecoa de forma ressignificada em tempos hodiernos apresentando-se como uma técnica a favor do grupo social hegemônico, sempre contida em uma relação de poder, onde inicialmente utilizou-se de teorias medico cientificas para alicerçar o argumento e certificar sua atuação social, dispondo das vidas e corpos daqueles que são alocados a margem da sociedade.

No tocante a pesquisa aqui apresentada, todo um aparato medico foi utilizado como forma de prender, punir e esconder aqueles que não se enquadravam a norma vigente ou eram pouco interessantes para sujeitos que detinham maior poder que aqueles que forma cerrados em hospitais psiquiátricos com 0 intuito de tratar suas "anomalias" da ordem do desejo. Segundo Foucault (2005, p. 294) "A soberania fazia morrer e deixar viver, eis que aparece um poder que eu chamaria de regulamentação e que consiste, ao contrário, em fazer viver e deixar morrer", tal afirmação resume o que fora colocado a princípio como objetivo deste estudo, a saber: compreender como a partir do desemaranhar das linhas componentes do dispositivo de controle social, sob o viés da patologização, componente da tríade pecado-crime-doença foi constituído o universo discursivo acerca das homossexualidades, tomando por alicerce as representações das homossexualidades masculinas a partir dos relatos (prontuários) produzidos por médicos psiquiatras vinculados ao sanatório Pinel no período compreendido entre os anos de 1920-1940. Ressalta-se que o comportamento e as percepções do corpo de tais pacientes foram identificados e classificados com o intuito de controlar e justificar a retirada de tais sujeitos do convívio social, sob uma égide discursivamente patologizante.

Logo, se pode compreender que o dispositivo que se transforma e ressignifica de maneira a sobreviver e melhor servir aos desejos dos grupos hegemônicos, fazendo uso de toda uma engrenagem e se alastrando de forma a tornar impossível que o ser não seja tido como sujeito em sua natureza (aquele que se assujeita a algo ou alguém), criando um sistema excludente e coercitivo que ainda vigora onde os discursos das instituições (Igreja, Estado, entre outros) ecoam e certificam a atuação e manutenção dos dispositivos históricos de controle social, fazendo com que os mesmos sejam introjetados pela sociedade gerando sujeitos dóceis e produtivos. 


\section{REFERÊNCIAS}

ALBUQUERQUE JÚNIOR, Durval Muniz de. A invenção do Nordeste e outras artes. 4.ed. São Paulo: Cortez, 2009. 376 p.

ALMEIDA, Angela Mendes de. 0 gosto pelo pecado: Casamento, sexualidade nos manuais de confissões dos séculos XVI e XVII. Rio de Janeiro: Rocco, 1992.

AMERICAN Psychiatric Association. Manual Diagnóstico e Estatístico de transtornos mentais. Washington, DC: American Psychiatric Association, 1952.

AMERICAN Psychiatric Association. Manual Diagnóstico e Estatístico de transtornos mentais. 2 ed. Washington, DC: American Psychiatric Association, 1968.

AMERICAN Psychiatric Association. Manual Diagnóstico e Estatístico de transtornos mentais. 3 ed. Washington, DC: American Psychiatric Association, 1980.

AMERICAN Psychiatric Association. Manual Diagnóstico e Estatístico de transtornos mentais. 3 ed. revisada. Washington, DC: American Psychiatric Association, 1987.

AMERICAN Psychiatric Association. Manual Diagnóstico e Estatístico de transtornos mentais. 4 ed. Washington, DC: American Psychiatric Association, 1994.

AMERICAN Psychiatric Association. Manual Diagnóstico e Estatístico de transtornos mentais. 4 ed., texto revisado. Washington, DC: American Psychiatric Association, 2000.

AMERICAN Psychiatric Association. Manual Diagnóstico e Estatístico de transtornos mentais. 5 ed. Washington, DC: American Psychiatric Association, 2013.

ANDERSEN, Niels Åkerstrøm. Discursive Analytical Strategies: Understanding Foucault, Koselleck, Laclau, Luhmann. Bristol: The Policy Press, 2003.

ANDERSEN, Niels Åkerstrøm; SKOUVIG, Laura. Knowledge Organization: a Sociohistorical Analysis and Critique. Library Quarterly, v.76, n.3, p. 22-300. 2006.

ARBEX, Daniela. Holocausto brasileiro. São Paulo: Geração Editorial, 2013.

BUDD, John. Discourse Analysis and the Study of Communication in LIS. Library Trends, v. 55, n.1, p. 65-83. 2006.

BUTLER, Judith. Cuerpos que importam: sobre os limites materiais e discursivos do sexo. Buenos Aires. Paidós, 2002.

BUTLER, Judith. Marcos de Guerra: las vidas Iloradas. Barcelona, Paidós Ibérica, 2010.

CHARAUDEAU, Patrick. Discurso das mídias. 2.ed.,São Paulo: Contexto, 2006.

CONSELHO FEDERAL DE PSICOLOGIA. Estabelece normas de atuação para os psicólogos em relação à questão da Orientação Sexual. Resolução n. 001/99 de 22 de março de 1999. 
DELEUZE, Gilles Deleuze ¿Que és un dispositivo? In: Michel Foucault, filósofo. Barcelona: Gedisa, 1990, p. 155-161.

DENIZART, Hugo. Engenharia Erótica: Travestis no Rio de Janeiro. Rio de Janeiro: Jorge Zahar ed., 1997.

FOUCAULT, Michel. An Interview with Michel Foucault. In Faubion, James D., ed., Power. V 3. New York: The New Press, 1994. p. 239-97.

FOUCAULT, Michel. História da sexualidade I: A vontade de saber. 16 ed. Rio de Janeiro, Edições Graal, 1988.

FOUCAULT, Michel. Nietzsche, Genealogy, History. In Rabinow, Paul, ed., The Foucault Reader. New York: Pantheon Books, 1984. p. 76-100.

FOUCAULT, Michel. Sobre a História da sexualidade. In: FOUCAULT, Michel. Microfísica do poder. Rio de Janeiro: Graal, 2000.

FOUCAULT, Michel. Vigiar e punir: nascimento da prisão. 30 ed. Petrópolis: Vozes, 2005.

GREEN, James; QUINALHA, Renan. Ditadura e homossexualidades: repressão, resistência e a busca da verdade. EdUFSCar. 2014.

GUIMARÃES, J. A. C. A dimensão teórica do tratamento temático da informação e suas interlocuções com o universo científico da International Society for Knowledge Organization (ISKO). Revista Ibero-americana de Ciência da Informação (RICI), Brasília, v. 1, n. 1, p. 77-99, 2008.

HJØRLAND, B. Domain analysis in information science: eleven approaches - traditional as well as innovative. Journal of Documentation, London, v. 58, n. 4, p. 422-462, 2002.

HJØRLAND, B. Information seeking and subject representation: an activity theoretical approach to Information Science. London: Greenwood Press, 1997.

HJØRLAND, B.; ALBRECHTSEN, H. Toward a new horizon in information science: domain-analysis. Journal of the American Society for Information Science, Washington, v. 46, n. 6, p. 400-425, 1995.

KOBASHI, N. Y. A elaboração de informações documentárias: em busca de uma metodologia. 1994. 163 f. Tese (Doutorado em Ciências da Comunicação) - Escola de Comunicação e Artes, Universidade de São Paulo, 1994.

MOTT, Luiz. Bahia: inquisição \& sociedade. Salvador: EDUFBA, 2010. 294 p.

NASCIMENTO, Francisco Arrais; LEITE JUNIOR, Francisco Francinete; Pinho, Fabio Assis. What gender is this? Challenges to the subject of representation about the gender boundaries. In: GUIMARÃES, José Augusto Chaves; MILANI, S. 0; DODEBEI, V. (Ed.). Knowledge organization for a sustainable world: Challenges and perspectives for cultural, scientific, and tecnological sharing in a connected Society. Würsburg: Ergon Verlag, 2016. p. 587-592. ISBN 978-3-95650-221-7

ORLANDI, Eni. (Org.). Discurso e políticas públicas urbanas - A fabricação do consenso. Campinas: Editora RG, 2010. 
ORLANDI, Eni. As formas do silêncio. Campinas: Editora Unicamp, 2002.

ORLANDI, Eni. Interpretação: autoria, leitura e feitos do trabalho simbólico. Petrópolis: Vozes, 1996.

POLLAK, M. Memória, Esquecimento, Silencio. In: Estudos Históricos, Rio de Janeiro, vol. 2, n. 3, 1989, p. 3-15. [versão em pdf, não paginada]. Disponível em: http://www.uel.br/cch/cdph/arqtxt/ Memoria_esquecimento_silencio.pdf). Acesso em: 14/07/2018.

PRINS, Baukje, MEIJER, Irene Costera. Como os corpos se tornam matéria: entrevista com Judith Butler. Revista Estudos Feministas. Volume 10, número 1, Florianópolis, janeiro de 2002, pp. 155167.

RICH, Adrienne. Compulsory Heterosexuality and Lesbian Existence. In: GELP, Barbara C. \& GELP, Albert (editores). Adrienne Rich's Poetry and Prose. New York/London: W.W. Norton \& Company, 1993.

ROLNIK, Suely. Cartografia sentimental: transformações contemporâneas do desejo. São Paulo: Estação Liberdade, 1989.

SCOTT, Joan Wallach. Gênero: uma categoria útil de análise histórica. In.: Educação e Realidade, Porto Alegre.1995.

SILVA, Redson dos Santos. "Sob cuidados médicos": homossexualidade masculina nos prontuários do Pinel (1920-1940). 2016. 156 f. Dissertação (Programa de Estudos Pós-Graduados em História) Faculdade de Ciências Sociais, Pontifícia Universidade Católica de São Paulo, 2016.

SPENCER, Colin. Homossexualidade: uma história. Rio de Janeiro: Record, 1999.

SPITZNER, Marcelo. Entre a memória e o silêncio, 0 testemunho tardio de um deportado homossexual. Anu. Lit., Florianópolis, v. 19, n. 2, p. 52-60, 2014. ISSN 2175-7917.

TENNIS, J. A convenient verisimilitude or oppressive internalization? Characterizing the ethical arguments surrounding hierarchical structures in knowledge organization systems. Knowledge Organization, Würzburg, v. 39, n. 5, p. 394-397, 2012. 